Received: 2018.08.09 Accepted: 2018.09.18 Published: 2019.01.11

Authors' Contribution: Study Design A Data Collection B Statistical Analysis C Data Interpretation D Manuscript Preparation E Literature Search F Funds Collection G

Corresponding Author: Source of support:

Background:

Material/Methods:

Results:

Conclusions:

MeSH Keywords:

Full-text PDF:

\title{
Fangchinoline Promotes Autophagy and Inhibits Apoptosis in Osteoporotic Rats
}

ABF Wenjun Zhu

CEF Wenge Ding

EF Xiaojun Shang

$A B$ Ding Zhu

ACDF Xiaoyu Dai
Department of Trauma Orthopedics, First People's Hospital of Changzhou Affiliated to Soochow University, Changzhou, Jiangsu, P.R. China

Osteoporosis is a common disorder leading to bone loss. At present, the treatment options available for the management of osteoporosis are limited. The present investigation evaluated the protective effect of fangchinoline against osteoporosis and also postulates the possible mechanism of action.

Osteoporosis was induced by subcutaneously injecting prednisolone $(2.5 \mathrm{mg} /$ pellet $)$ for 4 weeks. Fangchinoline 1,3 and $10 \mathrm{mg} / \mathrm{kg}$ was given intraperitoneally for the period. Protective effects of fangchinoline were assessed by estimating microarchitectural parameters and bone mineral density (BMD) in the vertebrae tissues, and biochemical parameters were also determined in the serum of rats with prednisolone-induced osteoporosis. Moreover, gene expression of microtubule-associated protein 1A/1B-light chain 3 (LC3), B cell lymphoma 2 (Bcl-2), caspase-3, bone morphogenetic protein 2 (BMP2), Beclin-1, autophagy-related 5 (ATG-5), Runt-related transcription factor 2 (RUNX-2), and receptor activator of nuclear factor kappa- $\beta$ ligand (RANKL) protein in the vertebrae tissue were assessed by reverse transcription-polymerase chain reaction (RT-PCR) and Western blot assay.

There was a significant $(p<0.01)$ decrease in the BMD and microarchitectural parameters in the vertebrae tissue of the fangchinoline-treated group compared to the prednisolone group. We also found that treatment with fangchinoline attenuated the altered expressions of LC3, BCl-2, caspase-3, BMP2, Beclin-1, ATG-5, RUNX-2, and RANKL protein in the prednisolone-induced osteoporosis rats. Moreover, levels of biochemical parameters were attenuated in the serum of fangchinoline-treated and prednisolone-induced osteoporosis rat. Histopathology revealed that the apoptosis of osteoblasts was decreased in the fangchinoline-treated group compared to the prednisolone group of rats.

Fangchinoline inhibits apoptosis of osteoblasts and protects against bone loss in prednisolone-induced osteoporosis rats by inducing autophagy.

Apoptosis • Autophagy • Methylprednisolone • Osteoporosis

https://www.medscimonit.com/abstract/index/idArt/912624

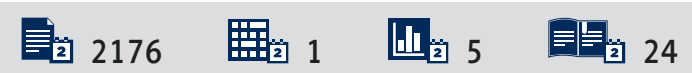




\section{Background}

Osteoporosis is a common bone disorder that affects over 2 billion people throughout the world [1]. Osteoporosis is characterized by decreased bone mass density; bone becomes fragile and structure of bone tissues is altered [2]. Postmenopausal osteoporosis in women results in increased risk of bone fracture. In China, $40.1 \%$ of women over age 50 years suffer from osteoporosis. Remodeling of bone is altered as osteoblastic bone formation is reduced and resorption of osteoclastic bone is increased [3]. Bone mineral density (BMD) is assessed in screening of osteoporosis [4]. Alterations in the bone microstructure and decreases in BMD result in lower mechanical strength, and micro-computed tomography (CT) is used to diagnose osteoporosis [5]. Several animal models have been established for osteoporosis and glucocorticoids induced osteoporosis is one of the commonest models of osteoporosis [6-8]. Literature reveals that bone matrix formation decreases and resorption of bone increases due to glucocorticoids treatment and thereby generation of osteocytes and osteoblasts decreases [9]. Moreover, glucocorticoid reduces autophagy and induces apoptosis in osteoblasts [10]. Glucocorticoid is reported to cause apoptosis by enhancing the expression of $\mathrm{Bcl}-2$ and downregulating the expression of $\mathrm{Bcl}-\mathrm{xl}[11]$.

In the past few decades alternative medicine has shown potential in the management of several disorders, including neuronal disorders. Fangchinoline is chemically an alkaloid isolated from Stephania tetrandra S. [12] and is reported to have antiinflammatory activity [13]. Fangchinoline attenuates the production of TNF- $\alpha$, IL- 6 , and IL- 1 and inhibits the activity of cyclooxygenase [14]. Fangchinoline has also has strong radical scavenging, hypotensive, anti-cancer, anti-oxidant, and antithrombotic activity [14-16]. Thus, the present investigation evaluated the protective effect of fangchinoline on bone loss and osteoporosis.

\section{Material and Methods}

\section{Animals}

Male Wistar rats (Weight: 180-200 gm; age: 4 weeks) were procured from Vital River Laboratories, China. Animals were kept in an environment with $60 \pm 5 \%$ humidity and temperature $26 \pm 2^{\circ} \mathrm{C}$ ) with a 12 -h night/day cycle. All the methods used on animals were approved by the Institutional Animal Care and Use Committee of the First People's Hospital of Changzhou Affiliated to Soochow University, China (IACUC/FPHC-SU/2017/09). We followed the guidelines of the Association for the Assessment and Accreditation of Laboratory Animal Care International (AAALAC) for experimentation and animal use.

\section{Chemicals}

Fangchinoline was procured from Sigma Aldrich (CA, USA). TRIzol reagent and CDNA synthesis kits were purchased from Thermo Fisher Scientific (MA, USA) and Lowry protein assay kits were procured from Bio-Rad Laboratories (CA, USA). The antibodies anti-Bcl-2 (1: 400), anti-caspase-3 (1: 500), antiBMP2 (1: 800), anti-Beclin-1 (1: 600), and anti-RANKL (1: 1000) were procured from Santa Cruz Biotechnology (TX, USA) and anti-LC3 (1: 1000) and anti-GAPDH (1: 1500) were from Cell Signaling Technology (MA, USA).

\section{Experimental}

All the animals were separated into 5 separate groups: (1) an untreated control group, (2) a prednisolone-treated group subcutaneously administered prednisolone ( $2.5 \mathrm{mg} /$ pellet) for 4 weeks, (3) a group administered $1 \mathrm{mg} / \mathrm{kg}$ fangchinoline i.p., (4) a group administered $3 \mathrm{mg} / \mathrm{kg}$ fangchinoline i.p., and (5) a group administered $10 \mathrm{mg} / \mathrm{kg}$ fangchinoline i.p. Later, the effect of fangchinoline on osteoporosis was evaluated.

\section{Assessment of bone mineral density (BMD) and structure analysis}

At the end of treatment protocol, isolation of the $5^{\text {th }}$ lumbar vertebrate (L5) was done and we fixed it with $1 \%$ formalin at room temperature overnight, followed by immersion in $70 \%$ ethanol for $2 \mathrm{~h}$ at room temperature. SCANCO imageprocessing language software was used by using a micro-CT instrument. A DCS-600 Aloka bone densitometer using dualenergy C-ray absorptiometry was used to estimate the BMD of isolated bone samples.

\section{Assessment of biochemical parameters}

Blood was collected from all the animals after anesthesia, and serum was separated out by centrifuging it for $10 \mathrm{~min}$ at 2000 rpm. Activity of alkaline phosphatase (ALP) and tartrate-resistant acid phosphatase (TRAP), as well as the concentration of phosphorus and calcium, was determined in the serum using auto-analyzer as per the instructions of the manufacturer. ELISA kits were used for determination of serum concentration of collagen type I fragments (CTX) and osteocalcin (OC) protein as per the protocol of the manufacturer.

\section{Reverse transcription-polymerase chain reaction (RT-PCR)}

At the end of the protocol, tibia tissues were isolated from all the animals and TRIzol reagent was used for the extraction of total RNA as per the instructions given by the manufacturer. cDNA was reverse-transcribed from RNA as per the instructions of the manufacturer of cDNA synthesis kit. The StepOne 
Real-Time PCR system was used to perform quantitative PCR, and GAPDH was used as an internal control. PCR was performed by thermocycling for $10 \mathrm{~min}$ at $95^{\circ} \mathrm{C}$, followed by 40 cycles for $15 \mathrm{~s}$ at $95^{\circ} \mathrm{C}$ and $45 \mathrm{~s}$ at $60^{\circ} \mathrm{C}$, and a final extension step of $95^{\circ} \mathrm{C}$ for $15 \mathrm{~s}, 60^{\circ} \mathrm{C}$ for $1 \mathrm{~min}, 95^{\circ} \mathrm{C}$ for $15 \mathrm{~s}$, and $60^{\circ} \mathrm{C}$ for $15 \mathrm{~s}$. Primers used were receptor activator of nuclear factor- $\mathrm{\kappa B}$ ligand (RANKL), autophagy protein (ATG) 5, Runt-related transcription factor (RUNX) 2, Beclin-1, Bone morphogenetic protein 2 (BMP2), and GAPDH. Comparative Cq method was used for the determination of relative gene expression and GAPDH as used as an internal control.

\section{Western blot analysis}

Tibia tissues at the end of the protocol were isolated from all the animals and ice-cold lysis buffer was homogenized with the tissues. Then, protease inhibitor supplemented with radioimmunoprecipitation assay lysis buffer was used to prepare the total cell lysates. Lowry protein assay kits were used for the determination of concentration of total protein from each of sample. Polyvinylidene difluoride membranes were used to transfer the separated protein samples by SDS-PAGE on a $10 \%$ gel. Then, membranes were incubated at $25^{\circ} \mathrm{C}$ for $2 \mathrm{~h}$ with the primary antibodies anti-LC3, anti-BCl-2, anti-caspase-3, antiBMP2, anti-Beclin-1, anti-RANKL, and anti-GAPDH. Then, horseradish peroxidase-conjugated IgG secondary antibodies were incubated with the membrane at $37^{\circ} \mathrm{C}$ for $1 \mathrm{~h}$. Quantity One software was used to quantify the density of blots.

\section{TUNEL staining assay}

In Situ Cell Death Detection kits were used to stain the isolated $5^{\text {th }}$ lumbar vertebrae as per the instructions given by the manufacturer. Each section of the vertebrae was separately dehydrated by treating at room temperature for $2 \mathrm{~h}$ using different concentrations of ethanol after fixing with formalin (10\%). TUNEL reagent was incubated with tissue sections at $37^{\circ} \mathrm{C}$ for $1 \mathrm{~h}$ and then hematoxylin and DAB were used to stain the tissue for 5 and $10 \mathrm{~min}$ at room temperature, respectively. Numbers of TUNEL-positive cells were determined in the tissue section by using a fluorescence microscope.

\section{Statistical analysis}

All data are expressed as mean \pm SEM $(n=10)$. The statistical analysis was performed using one-way ANOVA. Post hoc comparison of means was carried out by Dunnett's post hoc test (GraphPad Prism 6.1., CA, USA) for multiple comparisons. The level of statistical significance was set at $\mathrm{P}<0.05$.

\section{Results}

\section{Assessment of fangchinoline effect on microarchitectural parameters and BMD}

Figure 1 and Table 1 show the effect of fangchinoline on loss of bone as determined in lumbar vertebrae of prednisolone-induced osteoporosis rats by micro-CT analysis. Microarchitectural parameters such as bone surface density, trabecular bone tissue volume density, trabecular numbers, and trabecular number thickness were found to be significantly $(p<0.05, p<0.01)$ reduced in the prednisolone group compared to the control group of rats. However, treatment with fangchinoline significantly attenuated the altered microarchitectural parameters in lumbar vertebrae of prednisolone-induced osteoporosis rats. Bone mineral density in the prednisolone group $\left(0.128 \pm 0.007 \mathrm{~g} / \mathrm{cm}^{3}\right)$ was significantly lower than in the control group of rats $\left(0.297 \pm 0.013 \mathrm{~g} / \mathrm{cm}^{3}\right)$. There was a significant increase in the BMD in the fangchinoline-treated group by up to $0.273 \pm 0.017 \mathrm{~g} / \mathrm{cm}^{3}$ compared to the prednisolone group.

\section{Assessment of fangchinoline effect on biochemical parameters}

Assessment of effects of fangchinoline on biochemical parameters in the serum of prednisolone-induced osteoporosis rats is shown in Figure 2. There was a significant increase $(p<0.01)$ in the activity of ALP and TRAP and level of Ca, P, and CTX in the serum of prednisolone group rats compared to the control group rats. Moreover, the level of OC was significantly $(p<0.01)$ reduced in the serum of the prednisolone group rats compared to control group rats. However, treatment with fangchinoline attenuated the altered biochemical parameters, such as activity of ALP and TRAP and level of $\mathrm{Ca}, \mathrm{P}, \mathrm{OC}$, and CTX, in the serum of prednisolone-induced osteoporosis rats.

\section{Assessment of the of effect fangchinoline on gene expression of RANKL, ATG-5, RUNX-2, Beclin-1, and BMP2}

Assessment of the effect of fangchinoline on gene expression of RANKL, ATG-5, RUNX-2, Beclin-1, and BMP2 in the tibia tissues of prednisolone-induced osteoporosis rats is shown in Figure 3. Gene expression of ATG-5, RUNX-2, Beclin-1, and BMP2 was significantly reduced and expression of RANKL was significantly enhanced $(p<0.01)$ in the tibia tissues of the prednisolone group compared to the control group. However, treatment with fangchinoline significantly enhanced the gene expressions of ATG-5, RUNX-2, Beclin-1, and BMP2 and expression of RANKL was significantly reduced $(p<0.05, p<0.01)$ in the tibia tissue compared to the prednisolone group in a dose-dependent manner. 

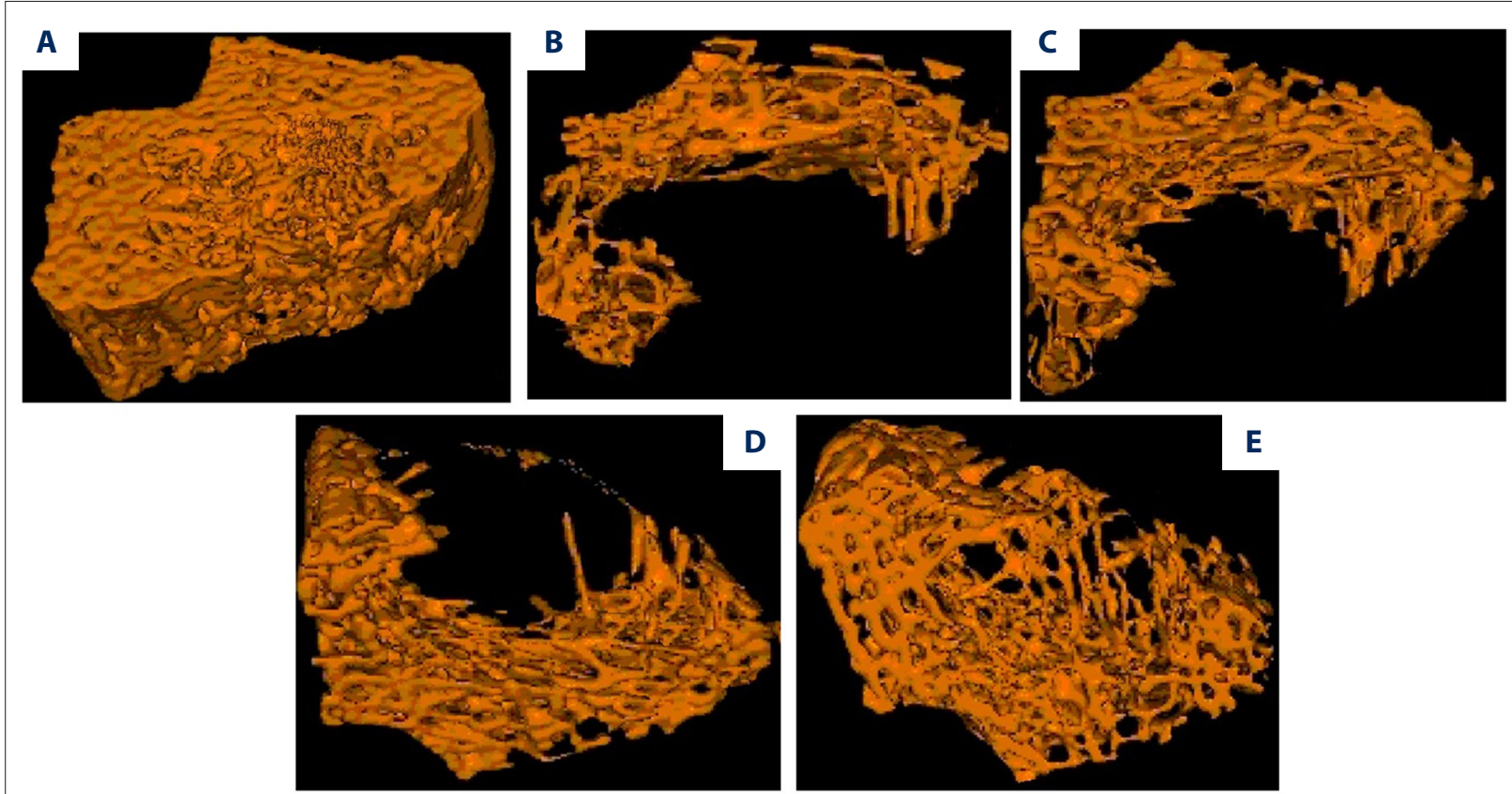

Figure 1. Assessment of effect of fangchinoline on 3D-reconstructed micro-CT images of the $5^{\text {th }}$ lumbar vertebrae of the prednisoloneinduced osteoporosis rats. (A) Control group; (B) Prednisolone group; (C) Fangchinoline $1 \mathrm{mg} / \mathrm{kg}$; (D) Fangchinoline $3 \mathrm{mg} / \mathrm{kg}$; (E) Fangchinoline $10 \mathrm{mg} / \mathrm{kg}$.

Table 1. Assessment of fangchinoline effect on microarchitectural parameters and BMD on the prednisolone-induced osteoporosis rat model.

\begin{tabular}{|c|c|c|c|c|c|c|}
\hline $\begin{array}{l}\text { Sr. } \\
\text { No. }\end{array}$ & Group & $\begin{array}{c}\text { Bone surface } \\
\text { density } \\
\left(\mathrm{mm}^{-1}\right)\end{array}$ & $\begin{array}{l}\text { Trabecular bone } \\
\text { tissue volume } \\
\text { density (\%) }\end{array}$ & $\begin{array}{l}\text { Trabecular } \\
\text { number } \\
\left(\mathrm{mm}^{-1}\right)\end{array}$ & $\begin{array}{l}\text { Trabecular } \\
\text { thickness } \\
(\mathrm{mm})\end{array}$ & $\begin{array}{c}\text { BMD } \\
\left(\mathrm{g} / \mathrm{cm}^{3}\right)\end{array}$ \\
\hline 1 & Control group & $3.92 \pm 0.42$ & $37.21 \pm 2.97$ & $1.42 \pm 0.036$ & $0.279 \pm 0.041$ & $0.297 \pm 0.013$ \\
\hline 2 & Prednisolone group & $2.36 \pm 0.28^{\# \#}$ & $22.49 \pm 1.42^{\# \#}$ & $0.83 \pm 0.028^{\# \#}$ & $0.246 \pm 0.017^{\#}$ & $0.128 \pm 0.007^{\# \#}$ \\
\hline 3 & Fangchinoline $1 \mathrm{mg} / \mathrm{kg}$ & $2.61 \pm 0.33$ & $26.33 \pm 1.69$ & $0.94 \pm 0.019$ & $0.258 \pm 0.023$ & $0.163 \pm 0.004^{\star}$ \\
\hline 4 & Fangchinoline 3 mg/kg & $3.17 \pm 0.29^{\star *}$ & $32.84 \pm 2.16^{\star *}$ & $1.27 \pm 0.023^{\star *}$ & $0.264 \pm 0.014^{\star}$ & $0.236 \pm 0.011^{\star *}$ \\
\hline 5 & Fangchinoline $10 \mathrm{mg} / \mathrm{kg}$ & $3.72 \pm 0.32^{\star *}$ & $36.42 \pm 2.46^{\star *}$ & $1.58 \pm 0.031^{* *}$ & $0.283 \pm 0.031^{*}$ & $0.273 \pm 0.017^{* *}$ \\
\hline
\end{tabular}

Mean \pm SEM $(n=10) .{ }^{\# \#} p<0.01$ vs. control group; * $p<0.05$ and ${ }^{* *} p<0.01$ vs. prednisolone group.

\section{Assessment of the effect of fangchinoline on the expression of LC3, Bcl-2, caspase-3, BMP2, Beclin-1, and RANKL}

Effect of fangchinoline on the expression of $\mathrm{LC} 3, \mathrm{Bcl}-2$, caspase-3, BMP2, Beclin-1, and RANKL protein in the tibia tissues of prednisolone-induced osteoporosis rats as shown by Western blot assay is shown in Figure 4. There was a significant decrease $(p<0.01)$ in the expression of $\mathrm{LC} 3, \mathrm{Bcl}-2, \mathrm{BMP} 2$, and Beclin-1 proteins in the tibia tissue of the prednisolone group compared to the control group. However, expression of caspase-3 and RANKL protein was significantly increased $(p<0.01)$ in the tibia tissue of the prednisolone group compared to the control group. Treatment with fangchinoline significantly attenuated the altered expression LC3, Bcl-2, caspase-3, BMP2, Beclin-1, and RANKL protein in the tibia tissue of prednisolone-induced osteoporosis rats.

\section{Assessment of the effect of fangchinoline on the number of TUNEL-positive cells}

Assessment of the effect of fangchinoline on the apoptosis of cells in lumbar vertebrae of prednisolone-induced osteoporosis rats as shown by TUNEL staining is shown in Figure 5. Apoptosis 

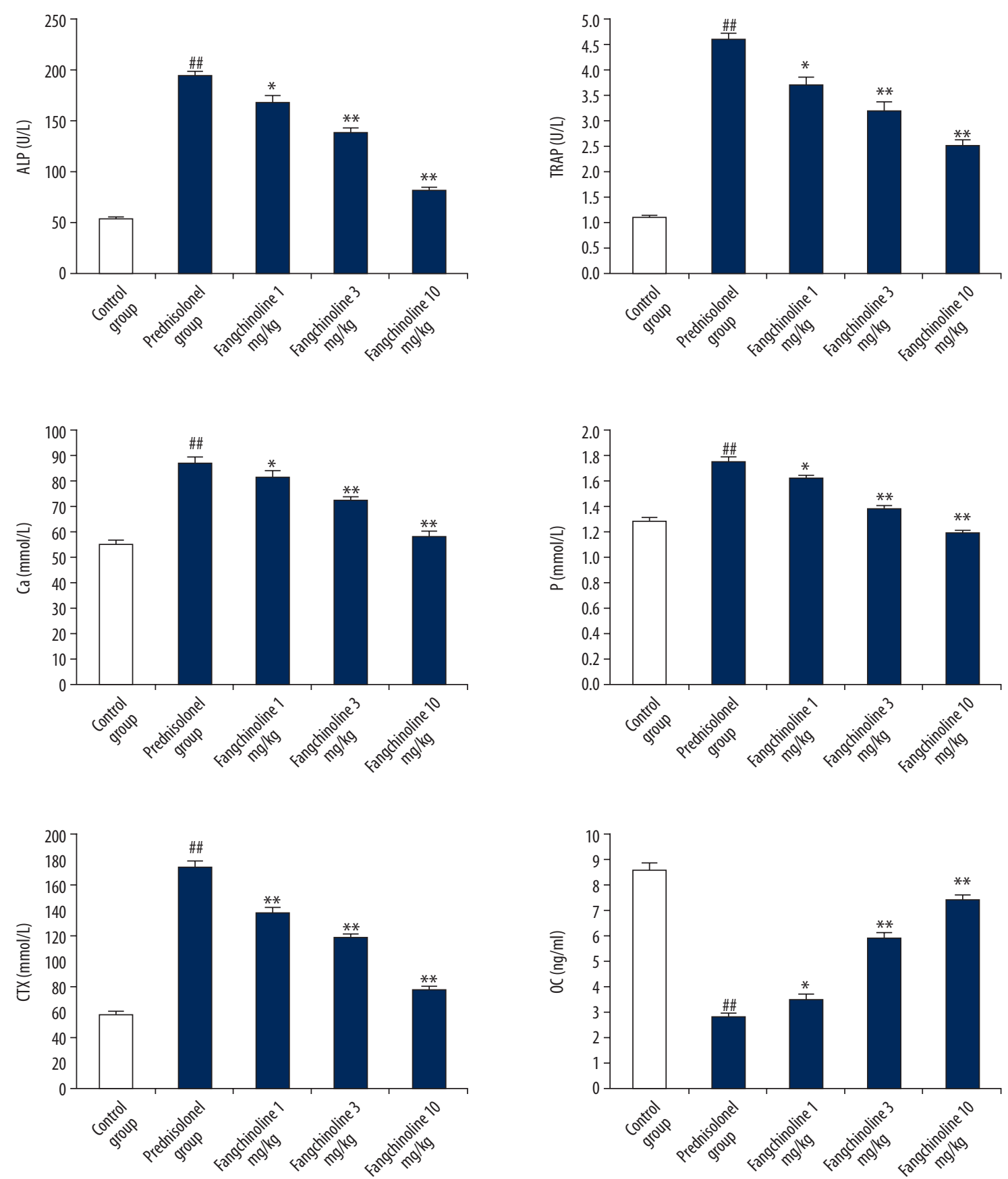

Figure 2. Assessment of effect of fangchinoline on biochemical parameters in the serum of prednisolone-induced osteoporosis rat model. Mean \pm SEM $(n=10),{ }^{\# \#} p<0.01$ vs. control group; ${ }^{*} p<0.05$ and ${ }^{* *} p<0.01$ vs. prednisolone group.

of cells was considered as directly proportional to the number of TUNEL-positive cells. There was a significant increase in the TUNEL-positive cells in lumbar vertebrae of the prednisolone group compared to the control group. However, TUNEL staining of TS of lumbar vertebrae showed a significant decrease in the number of TUNEL-positive cells in the fangchinoline-treated group compared to the prednisolone group. 

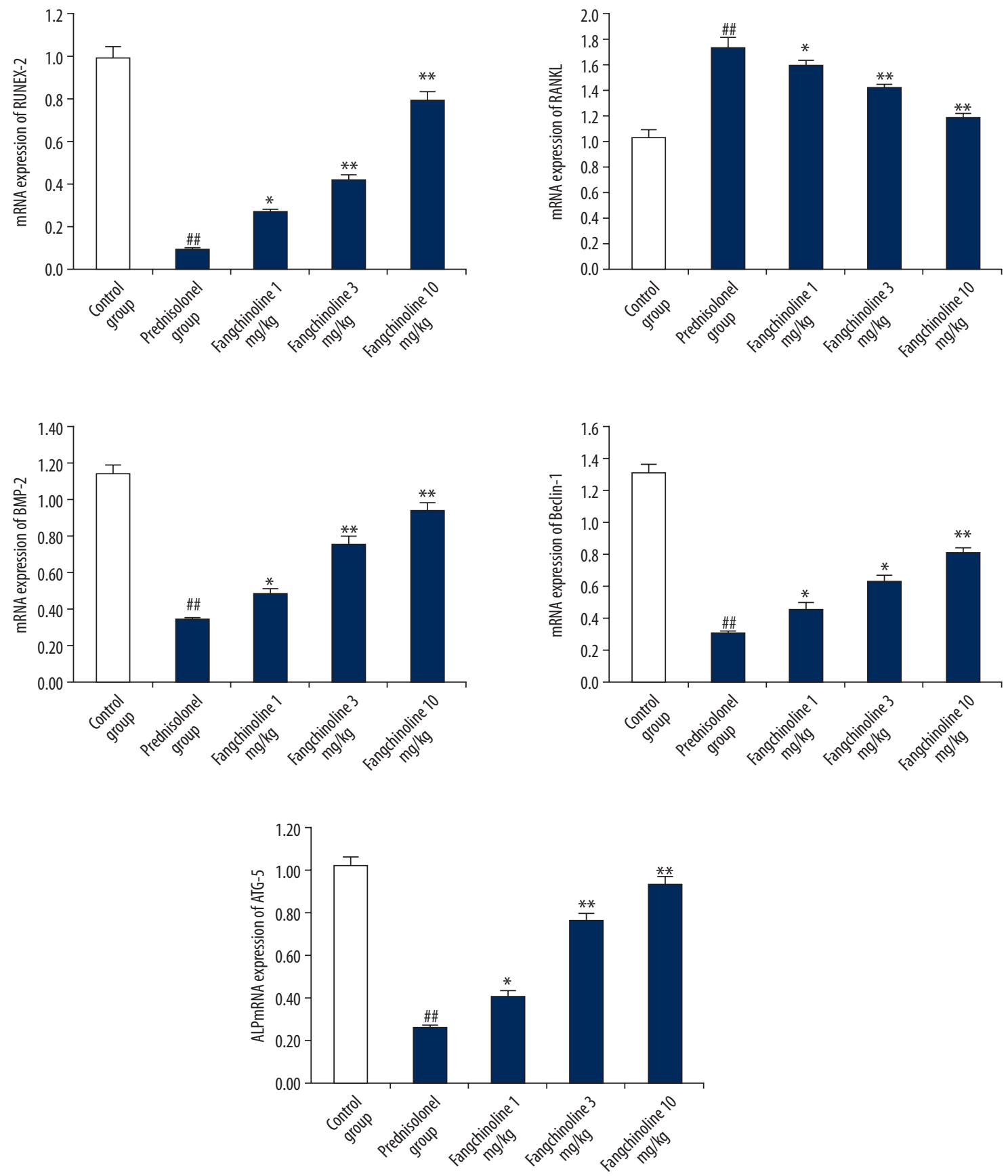

Figure 3. Assessment of the effect of fangchinoline on gene expression of RANKL, ATG-5, RUNX-2, Beclin-1, and BMP2 in the tibia tissues of prednisolone-induced osteoporosis rat model. Mean \pm SEM $(n=10)$, \#\# $p<0.01$ vs. control group; * $p<0.05$ and ** $p<0.01$ vs. prednisolone group.

\section{Discussion}

Osteoporosis is a common disorder that leads to bone loss, and the treatment options are limited. In last few decades, alternative medicine has gained interest in the management of several disorders, including osteoporosis. Thus, the present investigation evaluated the protective effect of fangchinoline against osteoporosis, and also explored the possible mechanism of its action. Osteoporosis was induced by injecting prednisolone for 4 weeks and fangchinoline was given for the 

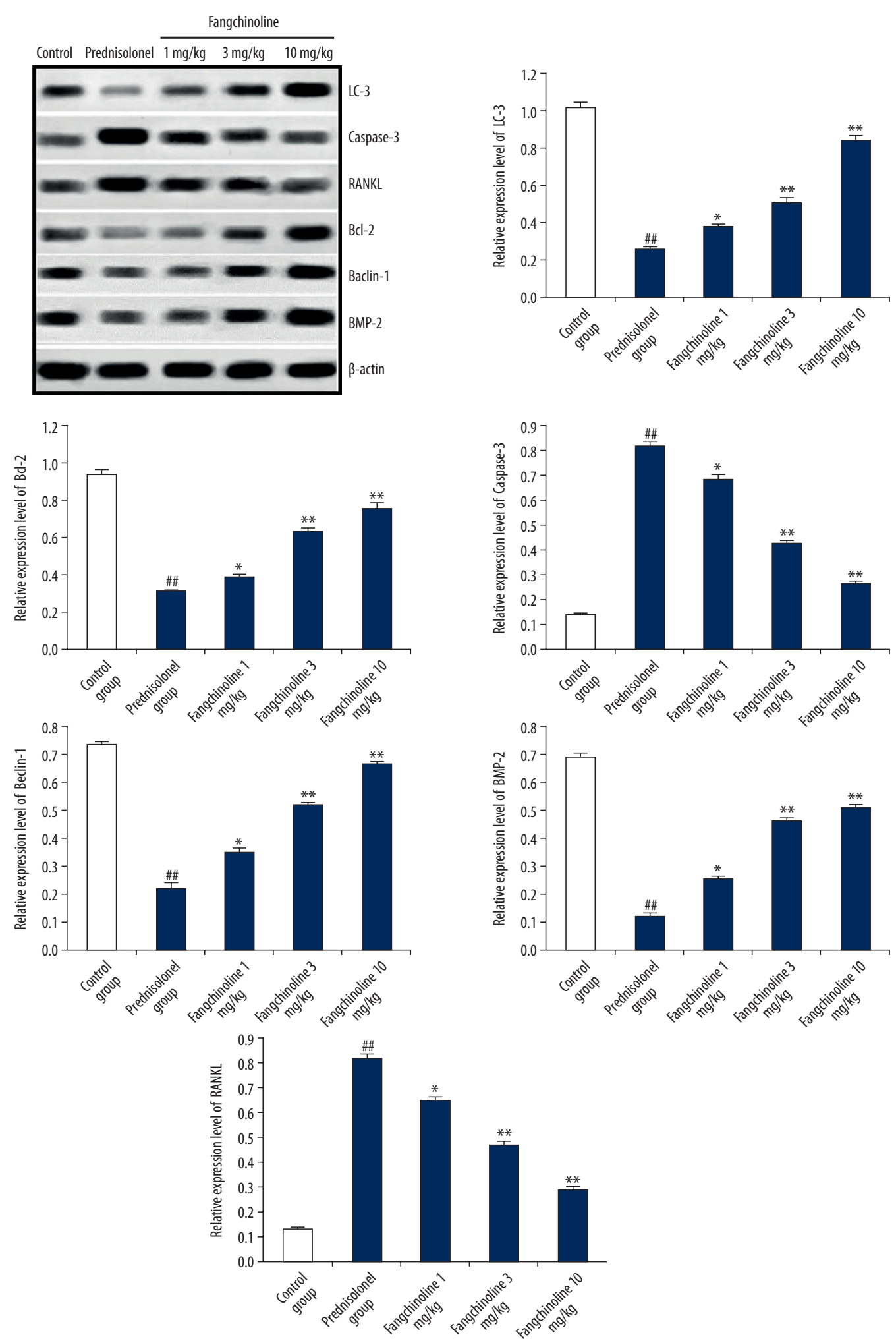

Figure 4. Assessment of effect of fangchinoline on expression of LC3, Bcl-2, caspase-3, BMP2, Beclin-1, and RANKL in the tibia tissues of the prednisolone-induced osteoporosis rat model. Mean \pm SEM $(n=10),{ }^{\# \#} p<0.01$ vs. control group; * $p<0.05$ and ${ }^{* *} p<0.01$ vs. prednisolone group. 


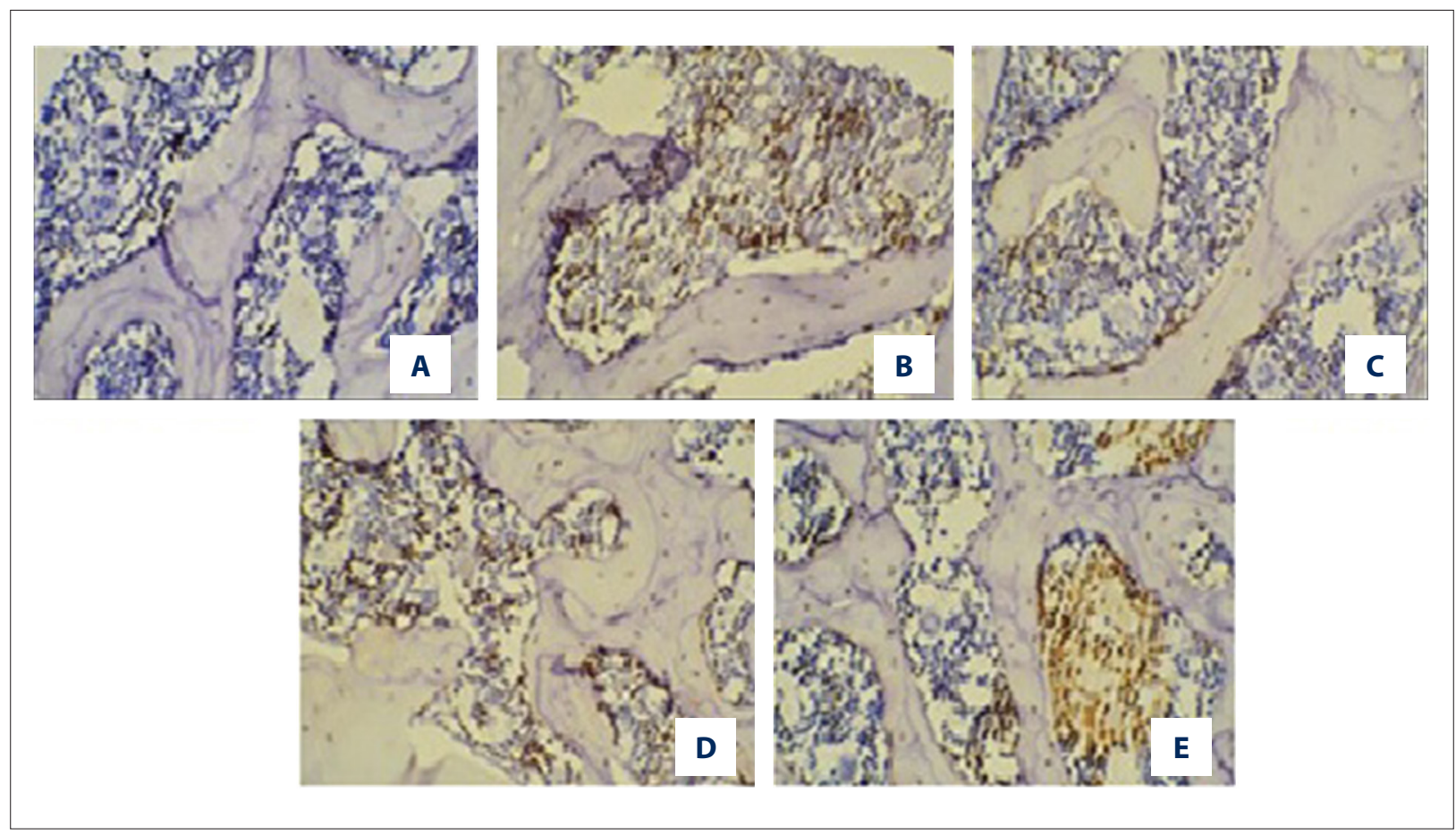

Figure 5. Assessment of the effect of fangchinoline on apoptosis of cells in lumbar vertebrae of prednisolone-induced osteoporosis rat model by TUNEL staining. (A) Control group; (B) prednisolone group; (C) Fangchinoline $1 \mathrm{mg} / \mathrm{kg}$; (D) Fangchinoline $3 \mathrm{mg} / \mathrm{kg}$; (E) Fangchinoline $10 \mathrm{mg} / \mathrm{kg}$.

period. The protective effect of fangchinoline was assessed by estimating microarchitectural parameters and BMD in the vertebrae tissues and gene expression of $\mathrm{LC} 3, \mathrm{Bcl}-2$, caspase-3, BMP2, Beclin-1, ATG-5, RUNX-2, and RANKL protein in the vertebrae tissue by RT-PCR and Western blot assay. Biochemical parameters were also determined in the serum of prednisolone-induced osteoporosis rats.

A previous study showed that prednisolone induced osteoporosis is a well-established osteoporosis rat model, as the level of biochemical parameters in the serum was altered and there was decreased BMD [17]. We found that that treatment with fangchinoline significantly attenuated the altered level of biochemical parameters in the serum and also improved BMD in the vertebrae of prednisolone-induced osteoporosis rats. Microarchitecture of bone was also reported to be altered in prednisolone-induced osteoporosis rats and thereby reduced the bone strength [18]. Treatment with fangchinoline attenuates the altered microarchitectural parameters in the vertebrae of prednisolone-induced osteoporosis rats.

The literature reveals that osteoblasts secrets BMP2, which regulates the mineralization and proliferation of osteoblasts [19]. Moreover, activation of osteoclast cells by the expression of RANK and expression of RUNX-2 is reported to be involved in osteoporosis [20]. Our study reveals that treatment with fangchinoline attenuates the expression of BMP-2, RANKL, and RUNX-2 protein in the vertebrae tissues of prednisoloneinduced osteoporosis rats in a dose-dependent manner.

In prednisolone-induced osteoporosis rats, several mechanisms are involved in the apoptosis of osteoblast cells [21]. It was reported that the expression of proapoptotic and antiapoptotic factors such as caspase- 3 and $\mathrm{BCl}-2$, respectively, affected apoptosis of osteoblasts [22]. Drugs used for the management of osteoporosis attenuate the expression of caspase- 3 and $\mathrm{Bcl}-2$ in osteoblasts and thereby prevent bone loss [23]. Results of our study reveal that the expression of $\mathrm{Bcl}-2$ was significantly enhanced and the activity of caspase- 3 was reduced in the fangchinoline-treated group compared to the prednisolone group in a dose-dependent manner. Autophagy is also one of the mechanisms involved in the development of osteoporosis, and several proteins, such as LC-3, ATG-5, and Beclin-1, are reported to be regulatory proteins of autophagosome [24], and treatment with fangchinoline attenuates the expression of several altered proteins, such as LC-3, ATG-5, and Beclin-1, in the vertebrae tissues of prednisolone-induced osteoporosis rats in a dose-dependent manner.

\section{Conclusions}

In conclusion, we found that fangchinoline inhibits apoptosis of osteoblasts and protects against bone loss in 
prednisolone-induced osteoporosis rats by inducing autophagy. Our results suggest that fangchinoline has strong activity against osteoporosis and could be a promising molecule for clinical study.

\section{References:}

1. Sözen T, Özışık L, Başaran NÇ: An overview and management of osteoporosis. Eur J Rheumatol, 2017; 4(1): 46-56

2. Osterhoff G, Morgan EF, Shefelbine SJ et al: Bone mechanical properties and changes with osteoporosis. Injury, 2016; 47(Suppl. 2): S11-20

3. Feng X, McDonald JM: Disorders of bone remodeling. Annu Rev Pathol, 2011; 6: 121-45

4. Berry SD, Samelson EJ, Pencina MJ et al: Repeat bone mineral density screening and prediction of hip and major osteoporotic fracture. JAMA, 2013; 310(12): 1256-62

5. Nishiyama KK, Shane E: Clinical imaging of bone microarchitecture with HR-pQCT. Curr Osteoporos Rep, 2013; 11(2): 147-55

6. Lelovas PP, Xanthos TT, Thoma SE et al: The laboratory rat as an animal model for osteoporosis research. Comp Med, 2008; 58(5): 424-30

7. Liu D-B, Sui C, Wu T-T et al: Association of bone morphogenetic protein (BMP)/Smad signaling pathway with fracture healing and osteogenic ability in senile osteoporotic fracture in humans and rats. Med Sci Monit, 2018; 24: 4363-71

8. Li H, Huang C, Zhu J et al: Lutein suppresses oxidative stress and inflammation by Nrf2 activation in an osteoporosis rat model. Med Sci Monit, 2018; 24: 5071-75

9. Jilka RL, Weinstein RS, Bellido T et al: Increased bone formation by prevention of osteoblast apoptosis with parathyroid hormone. J Clin Invest, 1999; 104(4): 439-46

10. Han Y, Zhang L, Xing Y et al: Autophagy relieves the function inhibition and apoptosis-promoting effects on osteoblast induced by glucocorticoid. Int J Mol Med, 2018; 41(2): 800-8

11. Qian Y-H, Xiao Q, Chen H, Xu J: Dexamethasone inhibits camptothecininduced apoptosis in C6-glioma via activation of Stat5/Bcl-xL pathway. Biochim Biophys Acta, 2009; 1793(5): 764-71

12. Tsutsumi T, Kobayashi S, Liu YY, Kontani H: Anti-hyperglycemic effect of fangchinoline isolated from Stephania tetrandra Radix in streptozotocindiabetic mice. Biol Pharm Bull, 2003; 26(3): 313-17

\section{Conflict of interest}

None.

13. Choi HS, Kim HS, Min KR et al: Anti-inflammatory effects of fangchinoline and tetrandrine. J Ethnopharmacol, 2000; 69(2): 173-79

14. Kim HS, Zhang YH, Oh KW, Ahn HY: Vasodilating and hypotensive effects of fangchinoline and tetrandrine on the rat aorta and the stroke-prone spontaneously hypertensive rat. J Ethnopharmacol, 1997; 58: 117-23

15. Kim HS, Zhang YH, Yun YP: Effects of tetrandrine and fangchinoline on experimental thrombosis in mice and human platelet aggregation. Planta Med, 1999; 65(2): 135-38

16. Gülçin I, Elias R, Gepdiremen A et al: Antioxidant activity of bisbenzylisoquinoline alkaloids from Stephania rotunda: Cepharanthine and fangchinoline. J Enzyme Inhib Med Chem, 2010; 25(1): 44-53

17. Briot K, Roux C: Glucocorticoid-induced osteoporosis. RMD Open, 2015; 1(1): e000014

18. Yao W, Cheng Z, Pham A et al: Glucocorticoid-induced bone loss can be reversed by the actions of PTH and Risedronate on different pathways for bone formation and mineralization. Arthritis Rheum, 2008; 58(11): 3485-97

19. Chen G, Deng C, Li Y-P: TGF- $\beta$ and BMP signaling in osteoblast differentiation and bone formation. Int J Biol Sci, 2012; 8(2): 272-88

20. Boyce BF, Xing L: Functions of RANKL/RANK/OPG in bone modeling and remodeling. Arch Biochem Biophys, 2008; 473(2): 139-46

21. Gruver-Yates AL, Cidlowski JA: Tissue-specific actions of glucocorticoids on apoptosis: A double-edged sword. Cells, 2013; 2(2): 202-23

22. Akiyama T, Bouillet $P$, Miyazaki $T$ et al: Regulation of osteoclast apoptosis by ubiquitylation of proapoptotic BH3-only Bcl-2 family member Bim. EMBO J, 2003; 22(24): 6653-64

23. Jilka RL, O'Brien CA, Roberson PK et al: Dysapoptosis of osteoblasts and osteocytes increases cancellous bone formation but exaggerates bone porosity with age. J Bone Miner Res, 2014; 29(1): 103-17

24. Arakawa S, Honda S, Yamaguchi H, Shimizu S: Molecular mechanisms and physiological roles of Atg5/Atg7-independent alternative autophagy. Proc Jpn Acad Ser B Phys Biol Sci, 2017; 93(6): 378-85 